\title{
Effect of initial strengthening on recovery stress generation and isothermal relaxation processes in TiNi alloys
}

\author{
I.Yu. Khmelevskaya \\ Moscow Steel and Alloys Institute, Leninsky Prospect 4, Moscow 117936, Russia
}

\begin{abstract}
Recovery stress (RS) generation and forced isothermal relaxation processes in Ti-50.5 at. \% $\mathrm{Ni}$ and $\mathrm{Ti}-50.7$ at. \% $\mathrm{Ni}$ shape memory alloys were investigated using in situ $\mathrm{X}$-ray structure analysis, X-ray texture analysis, transmission electron microscopy and mechanical tests. The alloys were subjected to thermomechanical treatments (TMT) including cold rolling followed by postdeformation heating in the range from 400 to $700^{\circ} \mathrm{C}$ for obtaining partially recovered, completely polygonized or recrystallized B2-austenite structures. Specimens containing partially recovered, polygonized or recrystallized structures obtained by thermomechanical treatment (TMT) were deformed in tension by $3-12 \%$ strain inducing shape memory. When the austenite get low hardening by TMT or by deformation inducing SME, the RS generation is accompanied by elastic and plastic deformations. When the austenite get high hardening, the RS generation is accompanied by elastic deformation only. The isothermal RS relaxation is accompanied by elastic deformation of the austenite excluding the case of very high RS (>1000 MPa) and recovery strain during relaxation $(8-9 \%)$ when plastic deformation also takes place. During RS generation the reverse martensite transformation by the orientation variant «directly backwards» is restricted by external counteraction and other orientation variants can partially realize.
\end{abstract}

\section{INTRODUCTION}

Recovery stress (RS) is an important functional property of shape memory alloys. It generates in conditions of shape restoration at external counteraction. Mechanical behaviour of SMA at the recovery stress generation and relaxation is studied in details [1]. Structure and deformation mechanisms of these processes attracted less attention. It is known that on reaching a maximum recovery stress value a martensite relief in $\mathrm{Cu}-\mathrm{Al}-\mathrm{Mn}$ alloy disappears, i.e. $\mathrm{RS}$ generation process completes at $\mathrm{A}_{\mathbf{f}}{ }^{\sigma}$ temperature, and forced isothermal RS relaxation during following unloading at $\mathrm{A}_{\mathrm{f}}{ }^{\sigma}$ develops by austenite deformation [2]. At the same time there is no clear understanding of what structure and lattice orientation changes and deformation mechanisms accompany the RS generation and forced isothermal relaxation. It is shown that after the RS generation a two-way shape memory effect of «martensitic» type appears in Ti-Ni alloy [3]. It can be a consequence of the martensite plastic deformation during RS generation. However the residual martensite strain can be induced at a preliminary deformation stage. It is also important to know the peculiarities of an influence of the initial structure state formed by heat and thermomechanical treatment on the RS generation and isothermal relaxation processes. The present work is devoted to studies of the influence of preliminary alloy strengthening on recovery stress generation and forced isothermal relaxation in Ti-Ni shape memory alloys.

\section{EXPERIMENTAL}

Ti-50.5\% Ni $\left(M_{s}=28, M_{f}=0, A_{s}=40, A_{f}=50^{\circ} \mathrm{C}\right)$ and $\mathrm{Ti}-50.7 \% \mathrm{Ni}\left(\mathrm{M}_{\mathrm{s}}=-8, \mathrm{M}_{\mathrm{f}}=-24, \mathrm{~A}_{\mathrm{s}}=5, \mathrm{~A}_{\mathrm{f}}=15^{\circ} \mathrm{C}\right)$ shape memory alloys were investigated using in situ $\mathrm{X}$-ray structure analysis, texture analysis, transmission electron microscopy and mechanical testing. 
Induction vacuum-melted alloy ingots after hot pressing and rotation forging were warm - or cold drawn into wires of 0.9 or $1.2 \mathrm{~mm}$ in diameter. The wires were subjected to various thermomechanical treatments (TMT) including multi-pass cold rolling to bands of $0.2-0.25 \mathrm{~mm}$ in thickness followed by post-deformation heating at 400,500 or $700{ }^{\circ} \mathrm{C}$. These treatments create partially recovered, completely polygonized or recrystallized B2-austenite structures respectively.

Band specimens were deformed at room temperature in tension up to $3-3.5,5$ or $10-12 \%$ residual (after unloading) strain $\varepsilon_{\mathrm{i}}$ inducing a shape memory due to oriented stress-induced martensite formation and martensite reorientation. In the cases of $\varepsilon_{\mathrm{i}}=5$ or $10-12 \%$ a shape change was accompanied by a conventional deformation-induced hardening. The conditions of TMT and following tensile deformation allow to create various combinations of TMT - induced hardening and tensile deformation-induced hardening levels.

Then a part of the deformed specimens was cut and pinched in a special heating stage at X-ray diffractometer DRON 2.0, heated to $A_{f}{ }^{\circ}$ temperature $\left(100-120^{\circ} \mathrm{C}\right)$ for a maximum RS generation and isothermally unloaded at $\mathbf{A}_{f}{ }^{\circ}$ for a complete $\mathrm{RS}$ relaxation. The control experiments were heating of thermomechanically treated specimens to $A_{f}$ point or thermomechanically treated and deformed in tension specimens to $A_{f}$ point in conditions of free shape restoration. The schematic representation of the X-ray experiment is shown in Fig. 1 , where the points of interest are numbered. The martensite and austenite $X-$ ray line profiles were obtained by step scanning at numbered points, the $\mathrm{Fe}_{\mathrm{K}_{\alpha}}$ - radiation was used. The B2 - austenite X-ray line half-width, interplanar distances $d_{\mathrm{hkl}}$, extrapolated lattice parameter $a_{\mathrm{B} 2}$ as well as austenite and martensite $X$-ray line integral intensities were estimated.

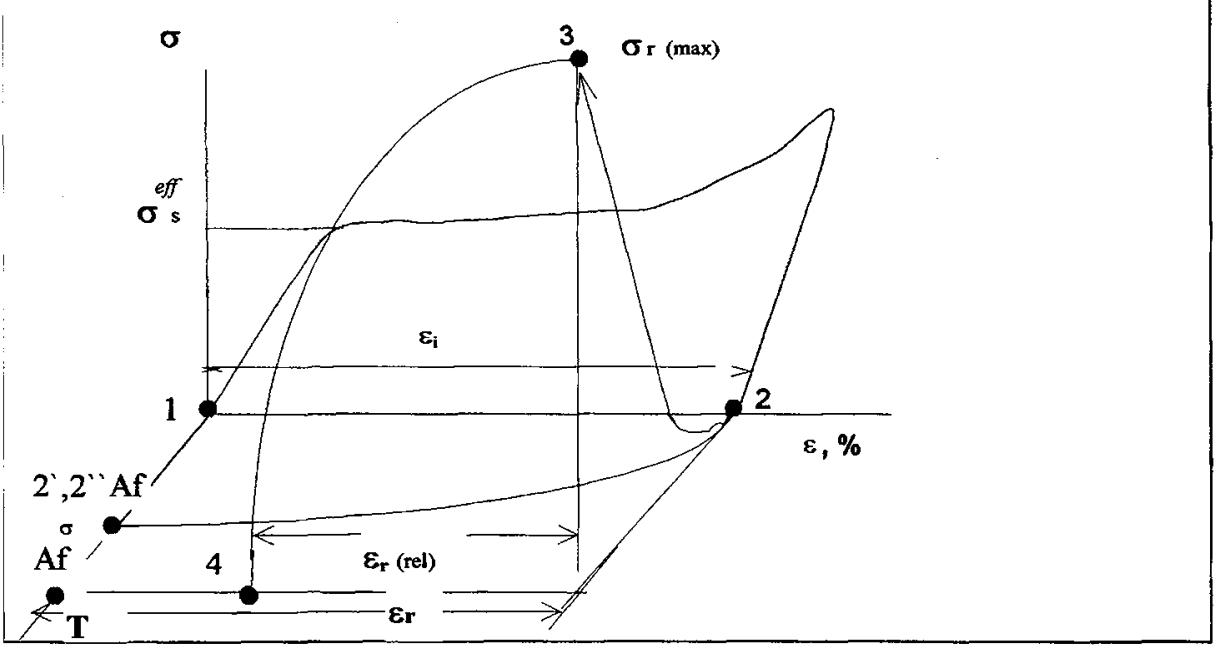

Figure1 - Schematic representation of the X-ray experiment.

1 - at room temperature after TMT; 2 - after tensile deformation and unloading at room temperature, $\varepsilon_{\mathrm{i}}-$ strain inducing SME, $2^{\prime}$ - near $\mathrm{A}_{\mathrm{f}}$ after reverse martensitic transformation; 2"- after free shape restoration near $A_{f}, \varepsilon_{\tau}$ - recovery strain; 3 - after maximum recovery stress $\sigma_{r}{ }^{\max }$ generation; 4 - after recovery stress isothermal relaxation, $\varepsilon_{\mathrm{T}}^{\mathrm{rel}}$ - recovery strain during relaxation.

Another part of specimens after tensile deformation inducing SME and unloading was pinched in the testing machine, heated to the $A_{f}$ point for a maximum RS generation and unloaded at this temperature for a forced isothermal RS relaxation. The following parameters were determined from mechanical tests: $\sigma_{\mathrm{r}}^{\max }$ - a maximum RS, $\varepsilon_{i}$ - an induced strain, $\varepsilon_{\mathrm{r}}{ }^{\mathrm{rel}}$ - recovery strain at maximum RS relaxation, $\sigma_{\mathrm{s}}^{\text {eff }}$ - an effective yield stress (see Fig. 1). A recovery strain $\varepsilon_{\mathrm{s}}$ was determined after free heating of deformed specimens to $\mathbf{A}_{\mathbf{f}}$ point. 
The elastic deformation was deduced from a comparison of B2-lattice parameter measured from rolling plane with the one measured in initial state. The plastic deformation was deduced from a comparison of the B2 X-ray line widths after recovery stress generation and relaxation with line width after free shape restoration.

Electron microscopic investigation was carried out at room temperature using $120 \mathrm{kV}$ «Tesla BS540» microscope. Thin foils were prepared from thermomechanically treated bands by window technics and initial structures were observed before the deformation inducing SME

The B2-austenite crystallographic textures were investigated at room temperature after RS generation and relaxation and after free shape recovery. The direct pole figures of $\{110\}_{\mathrm{B} 2}$ and $\{211\}_{\mathrm{B} 2}$ reflexes were obtained.

\section{RESULTS}

Electron microscopic investigation shows that preliminary thermomechanical treatment including plastic deformation and post-deformation heating at different temperatures leads to formation of different types of B2-austenite structure. Post-deformation heating at $400{ }^{\circ} \mathrm{C}$ is accompanied by recovery processes in the austenite but a dislocation density remains rather high, a polygonization does not yet develop. So, thermomechanical hardening is high in this case. After heating at $500{ }^{\circ} \mathrm{C}$ very fine equiaxed subgrains $0.1-$ $0.2 \mu \mathrm{m}$ in diameter are observed through the whole specimen. It is a polygonized structure which determines partial softening of the austenite. So, the thermomechanical hardening is moderate in this case. Heating at $700{ }^{\circ} \mathrm{C}$ leads to a complete recrystallization and maximum softening of the austenite.

During mechanical tests the maximum values of the $\sigma_{\mathrm{r}}^{\max }=1000-1200 \mathrm{MPa}$ were obtained after high strain inducing SME, $\varepsilon_{\mathrm{i}}=10-12 \%$, on specimens with polygonized austenite substructure. At the same time very high recovery strains at $\mathrm{RS}$ relaxation were obtained, $\varepsilon_{\mathrm{r}}^{\text {rel }}=8-9 \%$ (fig. 2a). Moderate values of $\sigma_{\mathrm{r}}^{\max }=500-900 \mathrm{MPa}$ were obtained after high strain inducing SME, $\varepsilon_{\mathrm{i}}=10-12 \%$, of specimens with recrystallized austenite, $\varepsilon_{\mathrm{i}}=5 \%$ strain of specimens with partially recovered substructure, low values of $\sigma_{\mathrm{r}}^{\max }=300-370 \mathrm{MPa}$ were obtained after $\varepsilon_{\mathrm{i}}=3-3,5 \%$ strain of specimens with polygonized and recrystallized structures (Fig. $2 \mathrm{~b}$ ). In the last two cases $\varepsilon_{\mathrm{r}}^{\text {rel }}$ was of $1-2 \%$.

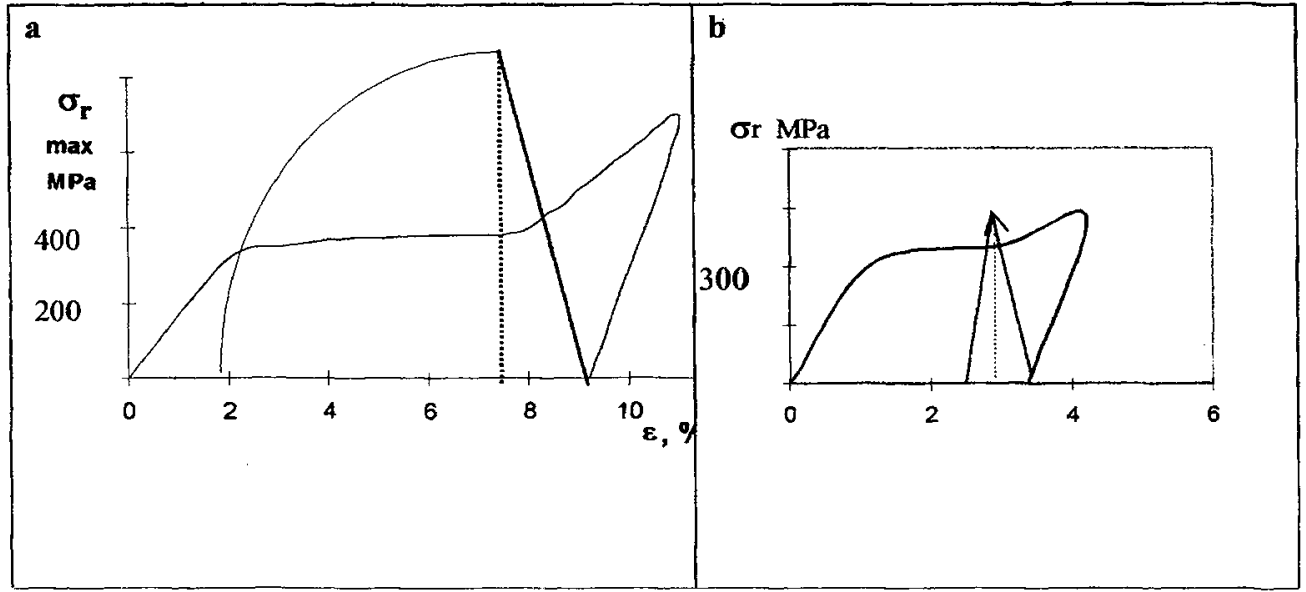

Figure 2 - Examples of strain, recovery stress generation and isothermal relaxation diagrams. a - Ti-50,7 $\% \mathrm{Ni}$ alloy, initially polygonized austenite, $\varepsilon \mathrm{i}=10-12 \%, \sigma_{\mathrm{r}}^{\max }=1200 \mathrm{MPa} . \mathrm{b}-\mathrm{Ti}-50,5 \% \mathrm{Ni}$ alloy, initially recrystallized austenite, $\varepsilon i=3-3.5 \%, \sigma_{\mathrm{r}}^{\max }=300 \mathrm{MPa}$. 
There are two main cases for tensile deformation inducing SME: the first one $\left(\varepsilon_{i}=5\right.$ and $\left.10-12 \%\right)$ results in «overdeformation» accompanied by conventional plastic flow, the second one $\left(\varepsilon_{\mathrm{i}}=3 \%\right)$ brings no "overdeformation». The first case is characterized by incomplete strain recovery during heating to $A_{f}$ point. In the second case strain recovery is complete.

According to X-ray study at room temperature the structure of the alloy 2 after thermomechanical treatment was mainly austenitic, and the structure of the alloy 1 was partially austenitic and martensitic. The martensite volume fraction increases with the increase in heating temperature from 400 to $700{ }^{\circ} \mathrm{C}$. Therefore a comparison of $\mathrm{X}$-ray line widths after these treatments and heating to $\mathrm{A}_{\mathrm{f}}$ point is incorrect without taking into account a possible transformation-induced dislocation substructure. After inducing strains $\varepsilon_{\mathrm{i}}=5$ and $10-12 \%$ the structure of the alloy 1 becomes martensitic but after $\varepsilon_{\mathrm{i}}=3-3.5 \%$ approximately $10 \%$ of the austenite remains untransformed.

The elastic deformation accompanies both recovery stress generation and relaxation process in all cases, as it seen from the lattice parameter changes after tensile deformation, recovery stress generation and isothermal relaxation in the example shown in (Fig. 3).

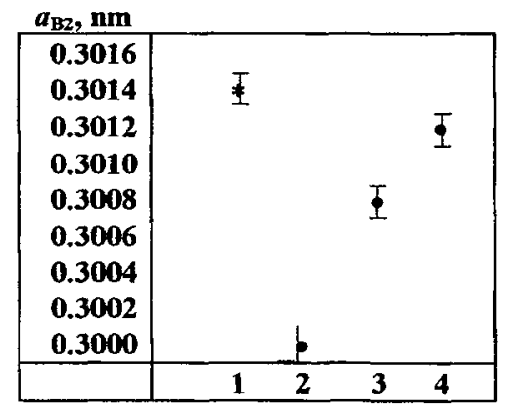

number of regime
Fig. 3. Lattice parameter of B2- austenite of $\mathrm{Ti}-50,7 \% \mathrm{Ni}$ alloy.

Initially polygonized austenite,

$\varepsilon_{\mathrm{i}}=10-12 \%$;

1 - initial state;

2 - after tensile SME deformation;

3 - after $\sigma_{r}{ }^{\max }$ generation near $A_{f}{ }^{\sigma}$ point;

4 - after recovery stress isothermal.

relaxation near $\mathrm{A}_{\mathrm{f}}{ }^{\circ}$ point.

The presence of plastic deformation depends on the hardening level of the austenite which can be evaluated approximately by $\sigma_{\mathrm{r}}^{\max }$ level (Fig. 4).

Low hardening of the austenite by thermomechanical treatment or by deformation inducing shape memory effect or combined before the recovery stress generation leads to elastic and plastic deformations during the recovery stress generation.

High combined hardening of the austenite by thermomechanical treatment or by deformation inducing shape memory effect or combined before the recovery stress generation leads to the absence of plastic deformation during the recovery stress generation.

Forced isothermal recovery stress relaxation develops by elastic deformation of the austenite mechanism excluding the case of very high recovery stress ( $>1000 \mathrm{MPa})$ and recovery strain during relaxation $(\sim 6-9 \%)$ when plastic deformation also takes place.

The austenite texture observed after high inducing strain and free shape restoration is rather week and complex due to complex thermomechanical prehistory (fig. 5). The crystallographic texture of the deformed austenite forming during recovery stress generation after high strains inducing $\operatorname{SME} \varepsilon_{i}=10-12$ $\%$, somewhat differs from the austenite texture after free shape restoration: the texture peaks are more weak and spread along $\beta$ angle resembling a ring texture. So, in the case or recovery stress generation a recovery of the reverse martensitic transformation by the orientation variant «directly backwards» is restricted by external counteraction and other orientation variants partially set in. The said effect is not significant when $\varepsilon_{\mathrm{i}}=5 \%$. 


\begin{tabular}{|c|c|c|c|c|c|c|}
\hline & \multicolumn{2}{|l|}{$\begin{array}{l}\mathbf{B}_{\mathrm{B} 2(211)} \\
2 \theta\end{array}$} & $\begin{array}{c}\text { Alloy } \\
\text { structure, } \varepsilon_{i}\end{array}$ & $\begin{array}{l}\text { Strengthening by } \\
\text { deformation, } \\
\text { inducing SME }\end{array}$ & $\begin{array}{l}\text { Strengthening } \\
\text { by TMT }\end{array}$ & $\begin{array}{l}\sigma_{\mathrm{r}}^{\max }, \\
\mathrm{MPa}\end{array}$ \\
\hline $\begin{array}{c}0.3 \\
0.2 \\
0.1 \\
0 \\
-0.1\end{array}$ & $\begin{array}{lll}- & & 9 \\
- & & \\
- & & \\
- & 1 & \end{array}$ & & $\begin{array}{l}\mathrm{Ti}-50.5 \% \mathrm{Ni} \\
\text { austenite } \\
\varepsilon_{\mathrm{i}}=3-3.5 \%\end{array}$ & low & low & 300 \\
\hline $\begin{array}{c}0.3 \\
0.2 \\
0.1 \\
0 \\
-0.1\end{array}$ & - & $b$ & $\begin{array}{l}\mathrm{Ti}-50.5 \mathrm{Ni} \\
\text { polygonized } \\
\text { austenite } \\
\varepsilon_{\mathrm{i}}=3-3.5 \%\end{array}$ & low & moderate & 370 \\
\hline $\begin{array}{c}0.3 \\
0.2 \\
0.1 \\
0 \\
-0.1 \\
\end{array}$ & $\begin{array}{lll}- & & \\
- & & \\
1 & & \\
-6 & 1\end{array}$ & 1 & $\begin{array}{l}\text { Ti-50..5 Ni } \\
\text { recrystallized } \\
\text { austenite } \\
\varepsilon_{\mathrm{i}}=10-12 \%\end{array}$ & high & low & 600 \\
\hline $\begin{array}{c}0.3 \\
0.2 \\
0.1 \\
0 \\
-0.1\end{array}$ & i & 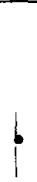 & $\begin{array}{l}\mathrm{Ti}-50.5 \mathrm{Ni} \\
\text { partially } \\
\text { recovered } \\
\text { austenite } \\
\varepsilon_{\mathrm{i}}=3-3.5 \%\end{array}$ & low & high & 500 \\
\hline $\begin{array}{c}0.3 \\
0.2 \\
0.1 \\
0 \\
-0.1\end{array}$ & - & $b$ & $\begin{array}{l}\mathrm{Ti}-50.7 \mathrm{Ni} \\
\text { recrystallize } \\
\text { austenite } \\
\varepsilon_{\mathrm{i}}=10-12 \%\end{array}$ & high & low & 900 \\
\hline $\begin{array}{c}0.3 \\
0.2 \\
0.1 \\
0 \\
-0.1\end{array}$ & -1 & $b$ & $\begin{array}{l}\text { Ti-50.7 Ni } \\
\text { recrystallize } \\
\text { austenite } \\
\varepsilon_{\mathrm{i}}=5 \%\end{array}$ & moderate & low & 600 \\
\hline $\begin{array}{c}0.3 \\
0.2 \\
0.1 \\
0 \\
-0.1\end{array}$ & 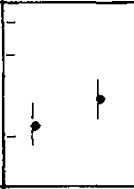 & $p$ & $\begin{array}{l}\mathrm{Ti}-50.7 \mathrm{Ni} \\
\text { polygonized } \\
\text { austenite } \\
\varepsilon_{i}=10-12 \%\end{array}$ & high & moderate & $\begin{array}{l}1200 \\
\text { high } \\
\varepsilon_{\mathrm{r}}^{\text {rel }}\end{array}$ \\
\hline & $2^{\prime \prime} \quad 3$ & 4 & & & & \\
\hline
\end{tabular}

Figure 4 - Comparison of X-ray line width of B2-austenite after free shape restoration, recovery stress generation and relaxation for different strengthening levels of $\mathrm{Ti}-50,5$ and $\mathrm{Ti}-50,7 \%$ alloys 

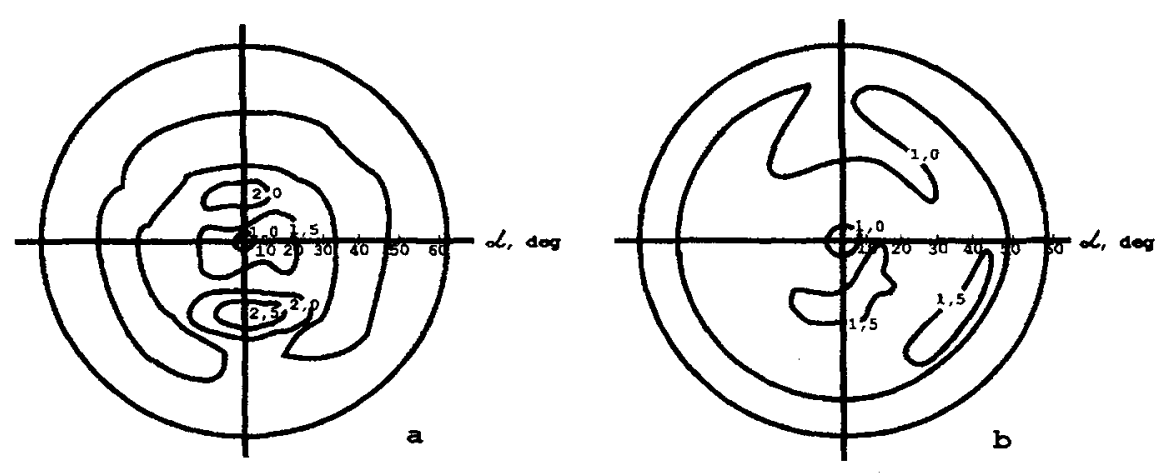

Figure 5 - Direct pole figures $\{211\}_{\mathrm{B} 2}$. Ti-50,7\% Ni alloy. Preliminary recrystallized austenite, induced strain $\varepsilon i=10 \%$. a - after free shape restoration; $\mathbf{b}$ - after recovery stress isothermal relaxation.

\section{CONCLUSIONS}

1. Low hardening of the austenite by thermomechanical treatment or by deformation inducing shape memory effect or combined before the recovery stress generation leads to elastic and plastic deformations during the recovery stress generation.

2. High hardening of the austenite by thermomechanical treatment or by deformation inducing shape memory effect or combined before the recovery stress generation leads to elastic deformation only during the recovery stress generation.

3. Forced isothermal recovery stress relaxation at $A_{f}$ point develops by elastic deformation of the austenite mechanism excluding the case ofvery high recovery stress $(>1000 \mathrm{MPa})$ and recovery strain during relaxation $(\sim 8-9 \%)$ when plastic deformation also takes place.

4. When the recovery stress is high, the reverse martensite transformation by orientation variant «directly backwards» is resricted by strong external counteraction and other orientation variants partially realize.

\section{ACKNOWLEDGMENTS}

The present work had been carried out under partial support of the Russian Foundation for Basic Research grant ${ }^{1}$ 96-15-98215 and of Moscow State Techical University (Ministry of Education of Russian Federation) grant.

\section{REFERENCES}

1. Likhachev, V.A.., Kuzjmin S.L. and Kamentseva, Z.P., 1987.Shape Memory Effect. LGU, Leningrad, 216 p. (in Russian).

2. Shipspa, V.G., Kazakov, V.Yu., Rjabikov, V.E. et al.,1993. Regularities of recovery stress generation and relaxation in CuAlMn alloy. Proceedings, XXIX International Seminar «Actual Problems of Strength», Pskov, p. 505-509 (in Russian)

3. Khmellevskaya I. Yu., 1984, Determining and Optimization of Shape Memory Effect Parameters in Experimental-Industrial Titanium Nickelide Based Alloys. Ph. D. Thesis, MISIS, Moscow, 163 p. (in Russian). 